\title{
PROTEGER OS ÍNDIOS E DESCOLONIZAR A PESQUISA: DARCY RIBEIRO COMO ANTROPÓLOGO
}

\author{
JOÃO PACHECO DE OLIVEIRA ${ }^{1}$
}

\begin{abstract}
RESUMO
Este artigo percorre de forma bastante sintética a produção antropológica de Darcy Ribeiro (1922-1997), contextualizando em termos históricos e intelectuais esta importante dimensão de seus trabalhos. Outros aspectos (literários e pedagógicos) de sua obra não foram considerados nesta análise. São apresentadas e discutidas algumas de suas principais ideias e orientações analíticas quanto à antropologia e ao indigenismo. Nas partes finais é realizada uma abordagem crítica que aponta os limites e contradições das interpretações que ele propõe. Paralelamente destaca a sua preocupação em definir para a antropologia brasileira um padrão acadêmico e profissional próprio, que permitisse conjugar 0 exercício da ciência com uma atitude ética e posicionada, aspectos que continuam a ser inspiradores para a antropologia e 0 indigenismo atual.
\end{abstract}

\section{PALAVRAS-CHAVE \\ Antropologia brasileira; Ética e antropologia; Política Indigenista.}

\section{Protect Indigenous and DECOLONIZE THE RESEARCH: DARCY RIBEIRO AS ANTHROPOLOGIST}

\begin{abstract}
This paper succinctly covers the anthropological production of Darcy Ribeiro (1922-1997), in order to contextualize the important dimension of his work in historical and intellectual terms. Some parts of his work did not fall into this focus. Thus it is presented and discussed some Ribeiro's main ideas and analytical guidance to the Anthropology and the indigenism. In the final parts, a critical approach is carried out to point out the limits and contradictions of the interpretations he proposed. At the same time, it stresses his concern to define a specific academic and professional standard for the Brazilian anthropology that would allow the exercise of science to be combined with an ethical and positioned attitude, aspects that continue to be inspiring for the Anthropology and the current indigenism.
\end{abstract}

\section{KEYWORDS}

Brazilian Anthropology; Activist anthropology; Indigenist policy.

\section{PROTEGÉR LES INDIENSET DÉCOLONISER LA RECHERCHE: DARCY RIBEIRO COMME ANTHROPOLOGUE}

\section{RÉSUMÉ}

Cet article couvre la production anthropologique de Darcy Ribeiro (1922-1997) de manière très synthétique, contextualisant en termes historiques et intellectuels cette dimension importante de son travail. D'autres aspects (litéraire, pedagogique) de son oeuvre ne sont pas considerés dans cette analyse, qui concerne l'anthropologie et l'indigénisme. Dans les dernières parties, une approche critique est menée qui met en évidence les limites et les contradictions des interprétations qu'il propose. Dans le même temps, il a un souci de définir un standard académique et professionnel spécifique pour l'anthropologie brésilienne, qui permettrait

\footnotetext{
${ }^{1}$ Professor Titular do PPGAS/Museu Nacional/UFRJ
} 
de combiner l'exercice de la science avec une attitude éthique et positionnée, aspects qui continuent d'inspirer l'anthropologie et l'indigénisme actuel.

\section{MOTS-CLÉS}

Anthropologie brésilienne; anthropologie impliquée; politique indigeniste.

\section{PROTEGER A LOS INDIOS Y DESCOLONIZAR LA INVESTIGACIÓN: DARCY RIBEIRO COMO ANTROPÓLOGO}

\section{RESUMEN}

Este artículo revisita la producción antropológica de Darcy Ribeiro (1922-1997) de una manera muy sintética, contextualizando en términos históricos e intelectuales esta importante dimensión de sus trabajos. Otros aspectos (literarios y pedagógicos) de su obra no entraran en este enfoque. Se presentan y discuten algunas de sus ideas principales y orientaciones analíticas con respecto a la antropología y el indigenismo. En las partes finales, se lleva a cabo un enfoque crítico que señala los límites y contradicciones de las interpretaciones que propone. Al mismo tiempo, se destaca su preocupación por definir un estándar académico y profesional propio para la antropología brasileña, que permitiera combinar el ejercicio de la ciencia con una actitud ética y posicionada, aspectos que continúan inspirando a la antropología y al indigenismo actual.

\section{PALABRAS CLAVE}

Antropología del Brasil; Ética y Antropología; Política Indigenista. 
É muito difícil isolar a obra de Darcy Ribeiro enquanto antropólogo da sua atividade literária e política. Mesmo as suas criações ficcionais estão plenas de personagens e temas resultantes de suas pesquisas com os indígenas do Brasil; por outro lado ele não separa valor científico e literário, considerando que a grandeza de algumas obras não prescinde de sua linguagem literária (RIBEIRO, 1979b, p. 9-10). A sua antropologia também está interconectada com um forte engajamento político, a sua atuação indigenista (sobretudo nos anos 50, por seu vínculo com o SPI) sendo indissociável dos estudos antropológicos que escreveu.

Mas se, dadas as limitações de tempo e espaço², insistirmos em focalizar os seus trabalhos escritos mais nitidamente voltados para a antropologia, poderíamos distingui-los em quatro grupos. Primeiro, os de cunho etnográfico, resultantes de suas pesquisas entre os Kadiwéu e Urubu-Kaapor, feitas entre 1948 e 1957. Além de comunicações em congressos e diversos artigos em revistas, destacam-se dois livros, um sobre cada uma de suas experiências etnográficas: Religião e Mitologia Kadiwéu (1950) e Arte Plumária dos Índios Kaapor (1957), este escrito em parceria com Berta Ribeiro.

Segundo, os trabalhos sobre o processo de integração dos índios na sociedade brasileira, o que inclui diversos artigos, escritos originalmente entre os anos de 1954 e 1958, e mesmo um livro (A Política Indigenista Brasileira, 1962), os quais vem a ser posteriormente consolidados em um livro extenso, Os Índios e a Civilização, que sintetiza a sua visão sobre a história dos índios no Brasil, publicado em 1970.

Terceiro, os estudos mais gerais sobre o processo civilizatório nas Américas, escritos no exílio ou pouco após o seu retorno ao Brasil (O Processo Civilizatório: Etapas da Evolução Sócio-Cultural, 1968; Teoria do Brasil, 1972; As Américas e a Civilização. Estudos de Antropologia da Civilização, 1977a). São esforços quase enciclopédicos de sistematização, onde Darcy Ribeiro aplicava os esquemas evolucionistas de análise a uma gama bastante heterogênea de documentos sobre a história e a cultura de alguns países das Américas.

Quarto, seria uma linha de preocupação partilhada com sua primeira esposa e colaboradora de toda a vida, Berta Gleiser Ribeiro, que desaguaria na publicação da Summa Etnológica Brasileira (1986). Trata-se de uma coletânea de textos (em três volumes) que pretendia, no domínio específico da arte e da cultura material indígena, atualizar o enorme esforço de coleta e sistematização de dados realizado na década de 1940 por Julian Steward (Handbook of South American Indians, 1946).

\footnotetext{
${ }^{2}$ O texto foi inicialmente preparado para uma homenagem a Darcy Ribeiro, organizada por Gustavo Lins Ribeiro, então Diretor do Instituto de Ciências Humanas, durante as comemorações de 50 anos da Universidade de Brasília/UNB. Depois, traduzido para o espanhol, o apresentei em um seminário realizado no Museu Nacional de Antropologia y História, na cidade do México, em 2016. As alterações aqui realizadas são muito pequenas, correspondendo assim ao limite de tempo de uma conferência que dispunha para essas apresentações orais.
} 
Duas produções posteriores podem ser enquadradas nessa classificação, como os Diários Índios: Os Urubu-Kaapor (1996), que se relacionam diretamente com a sua fase etnográfica, e O Povo Brasileiro: a formação e o sentido do Brasil, escrito em 1995 durante um período de agravamento de sua saúde (ele faleceria apenas dois anos depois), no qual retoma a diretiva sistematizadora da terceira fase.

Sem dúvida o seu trabalho mais lido entre etnólogos e indigenistas, o mais citado e com maior número de edições em português e em muitas outras línguas, foi Os Índios e a Civilização. A repercussão e importância deste livro não se limita de modo algum aos antropólogos ou àqueles de algum modo interessados na problemática indígena brasileira. Os dados e análises apresentados articulam-se diretamente com os debates sobre a formação da nacionalidade. O livro é dirigido também a um público mais amplo, afastando-se das interpretações idealizadas e harmônicas, solidárias com as concepções das elites que controlaram o Estado. Coloca em evidência, inversamente, os aspectos conflitivos, as desigualdades e preconceitos encontrados em nossa história. Assim Darcy põe no centro de suas preocupações o diálogo e a crítica das representações (letradas e cotidianas, eruditas ou de senso comum) sobre as "protocélulas" da formação de nossa nacionalidade, atribuindo ao indígena uma importância decisivamente nova.

Um livro como Os Índios e a Civilização pode ser colocado dentro de um conjunto seleto de obras que constituem uma referência básica para o pensamento social brasileiro, ao lado de clássicos como Casa Grande \& Senzala ou Raízes do Brasil, entre outros. As informações e opiniões que o livro articulou são hoje de ampla circulação. Repetidas e alteradas por uma legião de comentadores e divulgadores, atingem uma faixa da opinião pública muito mais extensa do que a de seus leitores diretos, servindo como inspiração e fundamento a muitas formulações procedentes de especialidades e interesses os mais diversos.

De certo modo o projeto de situar-se como uma continuidade dessa galeria de livros fundamentais para a nacionalidade não é algo estranho ao pensamento de Darcy Ribeiro. Embora reiteradamente ele ataque o conservadorismo de Gilberto Freyre e faça inúmeras críticas às teses sustentadas neste livro, ele nos afirma enfaticamente que esta foi "a obra mais importante da cultura brasileira [...] o maior dos livros brasileiros e o mais brasileiro dos ensaios que escrevemos". Ele destaca que "ao escrever este livro generoso, tolerante, forte e belo", Gilberto Freyre nos ensinou a nos reconciliarmos "com nossa ancestralidade lusitana e negra, de que todos nos vexávamos um pouco". Enfatiza, porém, que a imagem que Gilberto Freyre nos legou da nossa herança indígena ficou muito a desejar, sendo de aguardar que, baseado nos trabalhos recentes da etnologia brasileira, "alguém se abalance a essa tarefa armado da capacidade do escritor e do conhecimento científico necessário para realizá-la com engenho e arte" (RIBEIRO, 1979b, p. 11). Ainda que esta fosse a intenção explícita de $O$ 
Povo Brasileiro, é em Os Índios e a Civilização que Darcy Ribeiro mais consegue aproximar-se deste objetivo.

\section{DA MISTURA AO INDIGENISMO - A COMPOSIÇÃO DO LIVRO}

Diversos pensadores importantes enfatizaram a mistura das raças como uma característica da colonização portuguesa no Novo Mundo, tomando a figura do mestiço como uma síntese da nacionalidade. Darcy Ribeiro criticou a ideia de um ciclo evolutivo em que os índios, primeiros moradores das Américas, seriam absorvidos pela expansão da etnia nacional, associados aos contingentes de negros escravizados e imigrantes, e tenderiam a desaparecer dentro da população crescentemente homogeneizada da nova nação. Ele discordava de Capistrano de Abreu que, a partir de uma lista de antigas missões e aldeamentos na Bahia, apontaria a existência de um trânsito quase que natural das aldeias indígenas às vilas e depois às cidades, no curso do qual os índios iriam se civilizando e passando a ter uma condição não diferenciada dentro da sociedade nacional.

Contrapondo-se à "visão quase unânime dos historiadores brasileiros e até mesmo dos antropólogos que estudaram o problema", o autor considerava que o enfrentamento entre uma "etnia nacional em expansão" e "etnias tribais a barrar seu caminho", não teria como seu desdobramento uma aculturação progressiva, que através da miscigenação, viesse a desembocar em uma assimilação daquelas antigas coletividades ameríndias. Ele argumentava, ao contrário, que "não houve assimilação das entidades étnicas, mas absorção de indivíduos desgarrados, ao passo que aquelas entidades étnicas desapareciam, ou se transfiguravam para sobreviver" (RIBEIRO, 1977b, p. 424).

O objetivo mais geral do livro, segundo a definição do próprio autor, seria "alcançar uma compreensão acurada das situações de interação entre índios e frentes de expansão, a fim de chegar a generalizações significativas sobre o processo de mudança cultural" (RIBEIRO, 1977b, p. 12). Para isso foi necessário operar não a partir da simples reconstituição ou compreensão de situações específicas, mas sim do interesse "na análise das forças que as conformam", buscando definir uma "sequência-tipo" e determinar os fatores cruciais que operam no processo. Ou seja, foi preciso elaborar "um modelo hipotético do processo de transfiguração cultural" (RIBEIRO, 1977b, p. 218).

O plano da obra se apresenta dividido em três partes. Na primeira o autor procurou formar uma visão de conjunto do contato entre as sociedades indígenas e os segmentos da sociedade brasileira, representados estes pelas frentes de expansão de caráter agrícola, pastoril ou extrativista. A descrição do avanço das fronteiras foi feita em graus de profundidade histórica variável, focalizando basicamente o final do século XIX e o início do atual. As características econômicas e sociais dos diferentes tipos de frentes de expansão 
determinaram as diversas condições de interação que se estabeleceram entre índios e brancos na fronteira agrícola (a área da mata atlântica: o Sul e a Costa Leste), na fronteira pastoril (os campos e cerrados do Nordeste e partes de Goiás e Mato Grosso) e na fronteira extrativista (o Vale do Amazonas).

A sociedade nacional não se apresentou de modo homogêneo perante as etnias indígenas, as suas diferentes faces expressando-se através dos tipos distintos de frentes de expansão. As frentes extrativistas, pelo seu caráter difuso e pouco conectado com as instituições nacionais, permitiram formas particularmente arcaicas e despóticas de controle da mão de obra, bem como o empreendimento de ações muito agressivas que com frequência levavam à completa dissolução das etnias indígenas de que se aproximavam. A economia agrícola, tal como as frentes pastoris, não se interessou pelo índio como mão de obra, mas limitaram-se a disputar com eles as terras para expansão de suas atividades.

No estudo realizado por Darcy Ribeiro essas diferenças receberam um registro quantitativo, onde foi observado que $60 \%$ das etnias indígenas que se defrontaram com as frentes extrativistas estão atualmente extintas, comparando esses percentuais com os atingidos pelas frentes agrícolas $(45,7 \%)$ e pelas frentes pastoris (30,2\%). Em consequência ele concluiu que o determinante fundamental do destino dos grupos indígenas ега a dinâmica da própria sociedade nacional (RIBEIRO, 1977b, p. 437).

Na segunda parte foi considerada a interação entre índios e brancos enquanto resultado de uma ação intencional e dirigida por parte de organismos governamentais e religiosos. Apontando três atitudes que acarretaram resultados negativos para os índios - a etnocêntrica, a romântica e a absenteísta, Darcy Ribeiro aproximou as ideologias missionárias da atitude etnocêntrica, criticando a seguir a atitude romântica (que quer colocar o índio "em condições de estufa impossíveis de manter, inclusive porque os próprios índios contra elas se rebelariam" - RIBEIRO, 1977b, p. 195) e ainda a visão fatalista, que considerava o contato interétnico como uma fatalidade irreversível e aguardava apenas a assimilação ou a extinção dos indígenas. Caracterizou o indigenismo brasileiro pela superação dessas atitudes extremadas, propugnando por medidas que, resguardando o índio da extinção, o preparassem paulatinamente para interagir em igualdade de condições com os demais brasileiros" (RIBEIRO, 1977b, p. 195).

Descreveu a formação da agência indigenista brasileira, o SPI, criado em 1910 e extinto em 1967, inclusive com a cristalização de uma ideologia e de alguns princípios que norteavam as atividades locais do SPI. Foram relatados os principais episódios de pacificação de tribos arredias (Kaingang, Xokleng, Parintintim, Akwé-Xavante e Urubu-Kaapor), bem como indicado como tais fatos contribuíram para a formação da saga dos sertanistas e para consolidação das técnicas de campo no trabalho de atração e pacificação. Em um balanço final o autor observou que não conhecia nenhum Posto Indígena ou missão religiosa que 
tivesse respondido adequadamente aos desafios da proteção e assistência, mas ponderava que os postos indígenas em geral têm assegurado um espaço maior de liberdade para o índio manter sua própria organização social (RIBEIRO, 1977b, p. 211).

Na terceira parte foram mais detidamente analisadas várias das ideias e conceitos que organizaram a exposição anterior, como é o caso de transfiguração étnica, assimilação, acomodação, graus de integração, tipos de fronteiras, níveis de integração etc. Apoiando-se em suas pesquisas anteriores e utilizando-se de casos exemplares, imagens ricas e reiterações, o autor manifestava sua preocupação teórica e pedagógica, esclarecendo diversos aspectos das proposições que formulava. Lançando mão de dados referentes à situação dos indígenas entre 1900 e 1957, Darcy Ribeiro procurou apreender o impacto da sociedade nacional sobre as populações indígenas em diferentes planos e de acordo com as diferentes etapas de integração em que se encontravam. Ao final procedeu a uma fértil (e antológica!) discussão sobre o destino dos índios no Brasil, debatendo com outras interpretações de antropólogos contemporâneos e apresentando suas próprias ideias sobre o assunto.

\section{A TRANSFIGURAÇÃO ÉTNICA COMO PROCESSO}

Aos indígenas que conseguiram escapar ao extermínio, nenhuma oportunidade thes foi dada de preservar em sua forma original sua sociedade e cultura, seu meio ambiente e substrato biológico. Рara conseguir sobreviver essas etnias deviam responder a desafios urgentes, buscando preservar sua identidade e autonomia étnica, bem como "assegurar a continuidade de sua vida cultural mediante alterações estratégicas que evitem a desintegração de seu sistema associativo e a desmoralização completa do seu corpo de crenças e valores" (RIBEIRO, 1977b, p. 220-1). Esse processo adaptativo, que se impôs como imperativo aos indígenas que sobreviveram ao extermínio, fez com que eles permanecessem indígenas "já não nos seus hábitos e costumes, mas na auto-identificação como povos distintos do brasileiro e vítimas de sua dominação" (RIBEIRO, 1977b, p. 8).

É a isso que Darcy Ribeiro chamou de transfiguração étnica, afirmando que "o impacto da civilização sobre as populações tribais dava lugar a transfigurações étnicas e não a assimilação plena" (RIBEIRO, 1977b, p. 8). O foco principal do livro era justamente o estudo do processo de transfiguração étnica, pensado a partir de dados compulsados da experiência brasileira. Este, que não era um fato raro ou misterioso, mas um imperativo da situação de conjunção (RIBEIRO, 1977b, p. 221), foi o conceito-chave de Darcy Ribeiro para os dados e as análises apresentados em Os Índios e a Civilização.

Em primeiro lugar é necessário ter presente que a transfiguração étnica (à diferença da integração) não constituía um estado, mas sim um processo. A conceituação mais geral de 
transfiguração étnica dada por Darcy Ribeiro se encaminhava exatamente nessa direção, tratando-se de
"processo através do qual as populações tribais que se defrontam com sociedades nacionais preenchem os requisitos necessários a sua persistência como entidades étnicas, mediante sucessivas alterações em seu substrato biológico, em sua cultura e em suas formas de relação com a sociedade envolvente" (RIBEIRO, 1977, p. 13).

Para dar um estatuto teórico à noção de transfiguração étnica é preciso, diz Darcy Ribeiro, recorrer às ideias de níveis de integração e da hierarquia existente entre eles. Рara ele existiriam quatro níveis conceitualmente isoláveis da realidade: o ecológico; o biótico; o tecnológico e socioeconômico; o étnico-cultural e sociopsicológico. A ordem de enunciação por sua vez refletia uma hierarquia estabelecida entre esses níveis em termos de determinância (RIBEIRO, 1977b, p. 218-9). A função do pesquisador seria proceder a "sondagens" em cada um desses níveis, buscando detectar as forças condicionadoras da interação ali presentes; e muito embora o antropólogo tivesse como foco de investigação os dois últimos níveis, não poderia ignorar completamente as determinações que atuavam em um plano "pré-social".

Uma consideração ordenada e hierárquica dos vários níveis de interação permitia proceder a uma descrição adequada do processo de mudança social. A seleção dos elementos culturais a serem adotados por um grupo indígena em contato com a sociedade nacional seria precedida (em termos lógico-causais) pela adoção e/ou rearranjo de formas econômicas que a população indígena deveria estabelecer para de algum modo incorporarse ao sistema econômico regional.

Quando a sociedade nacional se alastrava sobre os territórios e os contingentes indígenas, ela o fazia, diz Darcy Ribeiro (1977b, p. 221), na forma de uma etnia nacional que não se estruturava para si própria, mas sim para o exercício de uma função econômica básica: servir ao sistema colonial. As forças econômicas passíveis de responder a tais pressões deveriam em outro plano ser compatíveis com formas socioculturais mantidas pelos indígenas; estas últimas precisavam em certa medida ajustar-se com algumas formas e valores socioculturais adotados pelos brancos. Todas essas compulsões (e antes da econômica ainda existe a biótica e a ecológica) definiriam um campo de possibilidades dentro do qual as etnias indígenas em interação com a sociedade nacional deveriam se mover para construir sua nova identidade e sua nova cultura.

\section{A CRÍTICA AO CULTURALISMO}

Nesse sentido a transfiguração étnica não podia mais ser pensada unicamente como um processo de mudança cultural, uma vez que o pesquisador deveria levar em conta tanto os fatores extra-locais (que condicionam a interação), quanto voltar a sua atenção em caráter 
prioritário para a construção de identidades sociais mais abrangentes. Nitidamente o autor distanciava-se de uma visão culturalista de grupo étnico - cuja crítica, realizada em 1969 pelo mais importante teórico da etnicidade, Fredrik Barth, representou uma radical mudança de rumo nos estudos sobre etnicidade. A sua definição de etnia indígena, pela forma dinâmica e não reificada que assumiu, aproxima-se desta perspectiva moderna - "... categorias relacionais entre agrupamentos humanos, compostas antes de representações recíprocas e de lealdades morais do que de especificidade culturais e raciais" (RIBEIRO, 1977b, p. 446).

Ao tratar essas identidades genéricas como objeto de estudo, Darcy Ribeiro, operando com uma análise simultaneamente histórica e comparativa, formulou uma importante questão que visava inspirar uma linha nova de investigações etnológicas: buscar, mais além do estudo localizado da manipulação de identidades em um grupo indígena, os mecanismos econômicos e sociológicos de exclusão e subordinação do índio.

O destino das populações indígenas, porém, é bem mais complexo do que julgavam os antropólogos e historiadores anteriores. Darcy Ribeiro afirmava com clareza - e essa é uma de suas principais contribuições teóricas e políticas - que a condição última do índio no Brasil não é em qualquer hipótese a sua "descaracterização cultural", a sua completa assimilação aos padrões modernos da sociedade brasileira (meta que nunca chegou a se realizar em qualquer um dos grupos indígenas considerados), mas a sua integração em condição econômica subordinada e na qualidade de "índios genéricos", isto é, "que quase nada conservam do patrimônio original mas permanecem definidos como índios e identificando-se como tais" (RIBEIRO, 1977b, p. 445). A identidade indígena seria preservada "se não como um corpo de conhecimentos uniformes, ao menos como uma sucessão particular de alterações, através das quais se mantêm a singularidade de cada etnia, apesar de sua crescente homogeneização" (RIBEIRO, 1977b, p. 226).

Quais seriam as razões para isso? Ele citava três: a) a "barreira interétnica"; b) "a falta de atrativos da vida dos dependentes de fazendas e seringais" (e hoje, poderia acrescentarse, a condição de trabalhador rural sem-terra); c) "a condição de estufa da intervenção protecionista ou missionária"3.

O fator fundamental para Darcy Ribeiro era a "barreira interétnica", algo que era ao mesmo tempo interior e exterior ao próprio indígena. O que, no entanto, a constituía? Ele respondia que era "o poder isolador do preconceito, racial e social", o qual se cristalizava "como uma técnica de competição ecológica, sustentada e mantida como requisito de dominação sobre grupos étnicos minoritários" (RIBEIRO, 1977b, p. 428). Daí que não existisse assimilação dos índios mesmo nos graus mais elevados de integração, mas sim um processo sucessivo de "acomodação penosa".

\footnotetext{
${ }^{3}$ Para uma reflexão sobre os impactos da ação indigenista, vide Cardoso de Oliveira (1972).
} 
Pensando sobre o futuro político do País e lembrando a possibilidade de que ocorresse uma "transformação revolucionária de suas estruturas" (RIBEIRO, 1977b, p. 429), ele mencionava que esta barreira era um produto histórico que poderia também se alterar caso novas condições se verificassem, com uma transfiguração tanto dos brasileiros quanto dos índios, estes últimos passando a ter então a liberdade de prosseguir como uma microetnia ou romper com sua identificação étnica e mergulhar na "etnia nacional" (RIBEIRO, 1977b, p. 429).

\section{DA HISTORICIZAÇÃO À ESSENCIALIZAÇÃO DO INDÍGENA}

Por que Darcy Ribeiro não teria levado essa perspectiva processualista e historicizante às últimas consequências? A resposta, primeiro de tudo, parece-me residir nas concepções evolucionistas subjacentes à obra do autor: as unidades sociais em contato interétnico mantinham-se como mônadas distintas e em diferentes estágios evolutivos.

É assim que Darcy Ribeiro concebia "etapas sucessivas e necessárias de integração das populações indígenas na sociedade nacional" (RIBEIRO, 1977b, p. 432), exibindo o que considerava ser a "sequência típica" do processo de transfiguração - que ia da tribo isolada até o grupo indígena integrado. As categorias que compunham tal sequência eram derivadas, porém, de saberes e procedimentos coloniais e administrativos, uniformizando situações históricas bem distintas, e não podendo, portanto, ser tratadas como instrumentos adequados de análise (PACHECO DE OLIVEIRA, 2016a).

Entendida como um fluxo histórico, com uma diretiva rigidamente fixada, a ideia de processo acabava perdendo seu potencial explicativo para vir a integrar-se em um projeto de "reconstituição da 'história natural' das relações entre índios e civilizados" (RIBEIRO, 1977b, p. 17). Ao contrário, o que as investigações contemporâneas estão procurando resgatar é justamente a multiplicidade de "histórias" que configuram a diversidade de formas organizativas dos indígenas atuais.

Em segundo lugar, o estudo de processos de transfiguração não conduz à compreensão de atores sociais concretos, mas a sua mera classificação em diferentes estágios evolutivos. A noção de transfiguração remeteria a um agente - o índio ou a etnia indígena - focalizando a interação segundo seus reflexos diretos ou mediatizados nas suas práticas e representações. Seria de esperar, portanto, que a tarefa do pesquisador fosse a de compreender como um falante - o índio - utilizava elementos de diferentes procedências, distinguindo-os e combinando-os em um discurso singular.

Na sua análise, porém, as coisas não se passavam desta forma, observando-se um empenho em reconstruir isoladamente os diferentes códigos que norteavam a conduta do índio e a do branco. Era em decorrência disso que ele, por exemplo, expressava seu ceticismo 
face às manifestações culturais dos índios do Nordeste, que thes pareciam como incorporação de costumes do universo católico europeu ou de cultos afro-brasileiros. Referindo-se aos Potiguara, por exemplo, diria com tristeza que até mesmo "os símbolos de sua origem indígena haviam sido adotados no processo de aculturação", em cujas danças eram utilizados instrumentos africanos - zambé y puita - "afirmando serem tipicamente tribais" (RIBEIRO, 1977b, p. 53) ${ }^{4}$. Em um outro texto ele censura a Gilberto Freyre pelo paralelo que estabeleceu entre índios e negros, atribuindo aos primeiros a introversão e a tristeza enquanto aos segundos corresponderia a alegria e loquacidade, afirmando que "sabidamente nunca viu índio que não fosse Fulniô de Águas Belas" (RIBEIRO, 1997, p. 6566). Efetivamente o modelo de índio com que operou Darcy Ribeiro identificava assim somente as culturas supostamente autênticas, prisioneiras, portanto da imagem colonial do índio bravo (que viria a ser pacificado pela Comissão Rondon e protegido pelo SPI).

Terceiro, a importância dos indígenas na história do Brasil continuou a ser algo relativo apenas ao passado. Assim Darcy Ribeiro descreveu no primeiro século a entrada de genes indígenas na formação da população nacional como um fator destacado, as mulheres indígenas predominando devido à relativa ausência de mulheres brancas e negras. Também nos primórdios da colonização, os indígenas assumiriam grande importância enquanto mão de obra, sendo escravizados e mantidos isolados de sua antiga etnia. Com o passar dos séculos, porém, a reprodução física e econômica da população brasileira teria se tornado algo inteiramente independente das mulheres e da força de trabalho indígena. A tendência a limitar a presença dos indígenas na história nacional somente aos primeiros séculos da colonização tem sido bastante criticada na investigação atual (PACHECO DE OLIVEIRA; ROCHA FREIRE, 2007).

Também aqui o caso dos índios do Nordeste é considerado dramático e sem esperanças, pois já não teriam importância cultural nem política pois "todas as terras já estão pacificamente possuídas pela sociedade nacional e os remanescentes tribais que ainda resistem ao avassalamento somente tem sentido como acontecimentos locais, imponderáveis" (RIBEIRO, 1977b, p. 57). Prognóstico que se revelou inteiramente errado, pois hoje os indígenas do Nordeste estão envolvidos em processos de revitalização cultural e renascimentos étnicos, as 10 etnias por ele listadas no início dos anos 70 hoje correspondem a mais de 40 (PACHECO DE OLIVEIRA, 2004).

Quarto, a argumentação de Darcy Ribeiro, ao abordar a temática da mistura, estabeleceu uma analogia equivocada em termos sociológicos e perigosa em termos políticos. No intuito de ser mais claro e contundente, o autor chega a dizer que "a condição de brasileiro e de indígena são de tal modo opostas e infranqueáveis" que "em certo sentido

\footnotetext{
${ }^{4}$ Para uma crítica dessa postura, vide Pacheco de Oliveira (2016c).
} 
constituem uma casta", com "barreiras intransponíveis a separá-los". "Identidades que só se adquirem pelo nascimento e só se dissipam pela morte" (RIBEIRO, 1977b, p. 57).

Se os antropólogos norte-americanos, ao falarem em aculturação e ao destacarem os aspectos recíprocos da interação entre etnias indígenas e sociedade nacional, elidiam os aspectos conflitivos e os mecanismos de dominação, de certo modo fornecendo aos seus leitores um anestésico para os cruéis processos de criação de dependência e de descaracterização cultural dos indígenas, Darcy Ribeiro chamava a atenção dos seus leitores inversamente para os aspectos segregacionistas das práticas interétnicas, mostrando que as compulsões sociais independiam da consciência dos atores (índios e brancos).

Ao cabo, o autor acabou por atribuir à fronteira entre índios e brancos um caráter substancialista, como um fato a-priorístico e imutável (o que colidia com a sua visão da barreira interétnica como um produto histórico). Tal desvio de rumo não deixava de ter um forte apelo político, pois a ideologia indigenista se reapropriava daquela analogia para expressar, de forma romântica e idealizada, a irredutibilidade da condição de indígena, funcionando quase que como uma compensação simbólica (ou psicanalítica) de um processo de dominação real.

\section{UM INTELECTUAL/ATOR}

Algumas vezes os intelectuais administram e contam a sua vida como se apenas escrevessem livros, fizessem pesquisas ou atuassem como professores. Sua história pessoal se anula face ao destaque monopolizador dado às suas obras, consideradas unicamente como totalidades coerentes, situadas de maneira abstrata em uma página dentro da história das ciências. Darcy Ribeiro não se enquadra de forma alguma neste padrão e seria injusto tentar avaliar por aí a sua contribuição à antropologia, à ciência ou à literatura no Brasil.

Diferente de muitos antropólogos eminentes (especialmente Lévi-Strauss, a quem ele em reiteradas vezes costumava contrapor-se), sua obra não é um sistema teórico abstrato e articulado, sua produção transita por diferentes disciplinas no campo das humanidades (antropologia, pedagogia, literatura) e suas intervenções práticas não estão distanciadas de seus escritos, nem tiveram uma importância menor. Menos que um perfil de teórico, criador de uma escola de pensamento, ou ainda um scholar, Darcy Ribeiro é um exemplo de intelectual/ator, que associa teorias e pesquisas com ações políticas de transformação, ambas acompanhadas por um complexo e apaixonado discurso justificador.

Foi enorme a influência de Darcy Ribeiro na definição das grandes linhas da política indigenista brasileira. Ingressando no SPI (Serviço de Proteção aos Índios) em 1947, ele absorveu muitas das ideias de Rondon e seus colaboradores, integrando-as com os ensinamentos da antropologia da época (o evolucionismo cultural norte-americano) e 
reapresentando-as em uma síntese própria, onde o pensamento do grupo anterior ali dominante (o sertanismo rondoniano) ganhava novas cores. O positivismo comtiano, ao qual se filiava Rondon, com suas facetas de cientificismo e conservadorismo, foi vivificado pelo relativismo antropológico e estabeleceu uma forte associação com a tradição romântica. Ele cunhou a expressão "humanismo rondoniano", reinterpretando o militar como um "humanista" e inserindo as suas linhas de ação dentro dos padrões do indigenismo mexicano.

Sua contribuição específica mais importante no campo do indigenismo foi a elaboração, em 1954, de um projeto para criação do Parque Indígena do Xingu. Ali, em colaboração com Roberto Cardoso de Oliveira (que foi quem escreveu o relatório que subsidiava a proposta), foi construída uma argumentação inovadora sobre a existência de terras tradicionalmente ocupadas pelos índios em virtude de seus usos e costume. Nesta perspectiva as terras indígenas não deveriam ser consideradas como um simples ato de outorga administrativa, à semelhança da atribuição de sesmarias ou a procedimentos burocráticos mais recentes para destinação de terras devolutas. Elas constituiriam o habitat de populações autóctones, cujas formas socioculturais o Estado brasileiro deveria encarregar-se de assegurar a preservação e continuidade.

Ao associar a definição de terras indígenas à manutenção de uma (valorizada) diversidade cultural, os formuladores da proposta de criação do parque indígena do Xingu ${ }^{5}$ propiciaram o fundamento de um dos atos e momentos mais importantes do indigenismo brasileiro. A argumentação elaborada foi inovadora e fecunda, sinalizando caminhos novos para a administração pública, a legislação e a jurisprudência no reconhecimento de direitos indígenas.

Durante quase duas décadas a interpretação corrente na agência indigenista limitou-se a nela enxergar apenas a condição de imemorialidade, associada à demonstração da posse permanente pelos indígenas, anterior a eventuais presenças do homem branco. Na Constituição de 1988 porém o critério atualizado foi o da tradição, elemento que correlacionava uma coletividade culturalmente distinta a uma certa parcela do território nacional. Foi isto que possibilitou, em torno da noção de terras tradicionais, o suporte legal para a reivindicação de territórios étnicos, o que ampliou a mobilização de outras populações tradicionais, com o surgimento de novos espaços e atores políticos (vide PACHECO DE OLIVEIRA, 2016c).

\section{CIÊNCIA E ÉTICA}

\footnotetext{
${ }^{5}$ Para uma discussão aprofundada do processo de criação do Parque do Xingu, vide Pires Menezes (2000).
} 
A leitura mais fértil de Os Índios e a Civilização, ao invés de pretender reportar-se a uma pressuposta unidade da obra de Darcy Ribeiro, deve referenciá-lo ao contexto intelectual e político dos anos 50, геcuperando as atividades desempenhadas na antiga Seção de Estudos do SPI, e à problemática teórica do contato interétnico, constituída ainda na década de 50 com o concurso de outros antropólogos, como Eduardo Galvão e Roberto Cardoso de Oliveira.

O nascimento dessa nova problemática coincidiu com o momento em que a cultura deixou de ser o objeto único de interesse dos antropólogos brasileiros, para deslocar-se igualmente para a questão da sobrevivência física e social das populações indígenas ${ }^{6}$. A mudança de foco teórico, contudo, não correspondia somente ao resultado de um desenvolvimento puramente conceitual, executado em um plano lógico-especulativo, mas tinha também raízes em uma prática de pesquisa vinculada a certo tipo de ação indigenista.

As questões que se impunham àqueles antropólogos e às quais eles procuravam aplicar seu instrumental teórico eram muitas e bastante heterogêneas: o apossamento das terras indígenas, a participação regular de índios enquanto força de trabalho de empreendimentos regionais, os graves desequilíbrios populacionais trazidos pelo contato e suas repercussões na vida sociocultural, o estabelecimento de vínculos com o mercado e a redefinição das necessidades, o entendimento sociológico da função dos postos indígenas e da intervenção protetora, etc. Esse comprometimento daqueles antropólogos não foi, então, de maneira alguma, um fato desvinculado do universo teórico.

Tratava-se ao contrário de um estímulo poderoso para que nessa reflexão crítica sobre as teorias da aculturação, a antropologia brasileira viesse a encontrar a originalidade de sua contribuição específica aos debates científicos internacionais, vindo a teorizar "pela primeira vez por sua própria conta e risco" (ZARUR, 1976, p. 6).

Por diversas vezes nos anos seguintes ao seu retorno para o Brasil, ele voltou a tocar nesse ponto, criticando ferozmente uma geração de antropólogos que em seus estudos sobre os indígenas do Brasil contentavam-se em aplicar as teorias e métodos elaborados por autores franceses, ingleses e norte-americanos. Ao ignorar as suas próprias interconexões com a realidade pesquisada, tais antropólogos estariam pretendendo transplantar mecanicamente as condições de produção de seus colegas metropolitanos, satisfazendo-se em copiar padrões científicos e em imitar a performance científica destes últimos: "As contribuições deles são palpites dados a um outro discurso, composto no estrangeiro para lá ser lido e admirado" (RIBEIRO, 1997, p. 41).

Para Darcy Ribeiro, ao contrário, a crítica ética e a ação política eram indissociáveis da elaboração teórica. Ele investe contra o relativismo cultural, considerando-o uma

\footnotetext{
${ }^{6}$ Para uma compreensão dos debates ocorridos inclusive no contexto de formação da Associação Brasileira de Antropologia/ABA, vide Pacheco de Oliveira (2001).
} 
consequência negativa da associação, no passado, da disciplina com o colonialismo. Se tal postura ajudou a apreciar mais favoravelmente outras culturas, esta antropologia - em suas palavras - "o que não faz é dar qualquer contribuição útil para vitalizar um valor real, afirmativo das culturas oprimidas; e muito menos de despertar na gente que as detém uma consciência crítica ou uma postura rebelde contra a ordem social que as explora e oprime. Em lugar disso o que faz é justificar o despotismo" (RIBEIRO, 1997, p. 22).

No curso de uma polêmica entrevista, no ano de 1978, ele serviu-se de uma imagem bastante sugestiva para expressar seu ponto de vista. Afirmava que, em meio aos escombros, à fome e ao medo de uma Berlim duramente bombardeada, não caberia ao antropólogo limitar-se a estudar a cultura de seus desesperados moradores, nem proceder ao inventário da cultura perdida:

\begin{abstract}
"O objetivismo cientificista [...] é como se alguém decidisse estudar em 1945 a forma da família alemã e a moral alemã em Berlim, 1945, debaixo das bombas, destruída dia e noite... [...]. Considerar que os costumes que se observam agora são os costumes tradicionais, sem se interessar pelo destino, a condição de vivência, a opressão que está sofrendo, é também uma atitude anticientífica" (RIBEIRO, 1979a, p. 95).
\end{abstract}

Ao utilizar-se desta metáfora para evidenciar a intensidade da violência sofrida pelos povos indígenas inseridos em uma situação colonial ${ }^{7}$, Darcy Ribeiro chamava os seus colegas - e aqui a lição deve ser estendida aos intelectuais e aos cientistas em geral - a um compromisso ético e à explicitação de suas posturas políticas e valores éticos: "Um antropólogo, cuja profissão é estudar povos, tem deveres éticos para com os povos que estuda" (RIBEIRO, 1979a, p. 95).

Ao rechaçar a crença na neutralidade da ciência, ele chamava atenção para a necessidade de que os antropólogos adotassem práticas novas em suas relações com os povos indígenas. A sua posição neste sentido veio a integrar-se plenamente com o grupo de antropólogos e intelectuais latino-americanos que formulou o chamado Documento de Barbados (1971), do qual aliás ele foi um dos signatários.

O pesquisador, argumentava Darcy Ribeiro, não podia ser mais um agente colonizador que, escondido atrás da neutralidade da ciência, carreasse a cultura dos nativos para os seus livros, filmes e museus, não estabelecendo compromissos éticos com a

\footnotetext{
${ }^{7}$ Por "situação colonial" não estou me restringindo apenas aos vínculos de natureza jurídica entre metrópole e colônia, tal como é usual entre os historiadores, mas a um contexto em que uma acentuada assimetria faz com que instituições e valores de uma coletividade (a dominada) sejam condicionados e definidos por outra (a dominante). Nesse sentido as relações coloniais estendemse muito além dos períodos coloniais, podendo descrever ainda a relação entre Estados Nacionais e povos indígenas.

${ }^{8}$ A proximidade afetiva e intelectual de Darcy com estes antropólogos permaneceu por muitos anos, sendo um fator pelo qual a terceira e última reunião deste grupo veio a ocorrer na cidade do Rio de Janeiro em 1993, enquanto ele exercia o cargo de vice-governador e secretário de cultura do estado. Os documentos dali resultantes, publicados fora do Brasil, permitem notar um distanciamento entre a postura estatizante e tutelar, assumida por seus pupilos brasileiros, e a perspectiva autonomista, já então predominante dentro do grupo (vide GRUNBERG, 1995).
} 
continuidade das instituições e costumes que estuda, assim como com o bem-estar e a dignidade dessas coletividades. Em uma linguagem direta e contundente, ele dizia que o antropólogo não podia ser um "gigolô de índio", mas precisava, ao contrário, preocupar-se em desenvolver formas pelas quais o conhecimento por ele acumulado pudesse reverter para as populações estudadas. Nesta perspectiva os dados obtidos nas pesquisas de campo (fotos, entrevistas, diários) ou produzidos a partir delas (como os livros e acervos científicos) deveriam ser utilizados no benefício dos próprios índios.

\section{OS ÍNDIOS BRASILEIROS E O INDIGENISMO HOJE}

Um livro como Os Índios e a Civilização, com uma problemática referida a um contexto histórico preciso e implicando um conjunto de ideias e propostas de intervenção prática, não é lido apenas como uma contribuição do passado. Os seus leitores certamente irão esperar informações e ideias sobre a situação atual e as alternativas que se apresentam hoje aos índios brasileiros. É impossível assim não trazer as propostas de Darcy Ribeiro para o contexto contemporâneo, acrescentando-lhe outros eixos de análise.

Em primeiro lugar, há que considerar a avaliação quanto à importância dos índios no Brasil contemporâneo. Darcy Ribeiro operava com uma estimativa de que a população indígena em 1957 estivesse entre 68.100 e 99.700 membros, constituindo uma parcela muito pequena $(0,02 \%)$ da população brasileira. A esta proporção limita-se as semelhanças, a partir daí iniciando-se os contrastes.

Nos dados por ele pesquisados (RIBEIRO, 1977b, p. 254-262) eram enumeradas 143 etnias, enquanto hoje se trabalha com o universo de 220 povos indígenas. A composição interna dessa população alterou-se radicalmente nas últimas quatro décadas. Em 1957 cerca de $57 \%$ dos índios eram considerados isolados e $10 \%$ das etnias tinham uma dimensão demográfica pequena (de menos de 250 membros).

Já na última década do século passado os dados indicavam que a maioria dos indígenas da Amazônia (68\%) pertenciam a etnias com mais de 2.000 membros, constituindo claramente populações bastante conhecidas a nível regional e com relações permanentes com os brancos e as agências governamentais. Ao contrário, as sociedades indígenas em pequena escala representavam apenas 3,4 \% dos índios da Amazônia e as etnias ainda consideradas isoladas não passavam de 27.

Torna-se necessária a incorporação de novas dimensões para pensarmos sobre os povos e culturas indígenas contemporâneos. Segundo o censo de 2001 a metade da população indígena tem hoje também alguma forma de residência (em tempo parcial, 
provisória ou definitiva) em pequenas cidades do interior ou mesmo nas grandes capitais ${ }^{9}, 0$ que thes coloca novos problemas e desafios, a serem respondidos por associações de características variadas. Há atualmente que levar em conta a existência de alguns milhares de jovens indígenas que já concluíram ou estão em vias de concluir cursos universitários (GOMES, 2009; AIRES, 2009; SANTOS, 2007). Um fenômeno importante e característico da atual conjuntura indígena brasileira é o ressurgimento de afirmações identitárias por parte de coletividades que, segundo uma leitura restritiva de fontes governamentais, aparentemente estariam assimiladas. Longe de ser um fenômeno exclusivo da faixa atlântica e das áreas de colonização mais antigas, isto ocorre extensamente também em outras regiões do País e inclusive na Amazônia.

À diferença de um passado recente, a identidade de indígena é hoje objeto de elevada autoestima, não só por parte de líderes políticos e religiosos, como expressão de um suposto tradicionalismo, mas também pelos mais jovens, como expressão de políticas públicas e processos identitários ligados à globalização. As identidades indígenas resultam de referências coletiva às origens (vividas sempre de modo variável, por referência à cultura) e são nesse sentido importantes âncoras intelectuais e afetivas no contexto atual. A atualização e recuperação de valores e dignidades ancestrais não é uma possibilidade aberta somente aos que nasceram em unidades sociais autônomas, isto é, fora das terras indígenas. As gerações nascidas nas reservas, assim como os descendentes de índios coloniais (tapuios, caboclos, índios de missões religiosas) as reivindicam igualmente.

Na estratégia política elaborada por Darcy Ribeiro era o Estado, através da agência oficial (o SPI), que devia contrapor-se ao mandonismo e ao arbítrio dos potentados locais frente aos índios (ainda incapazes de iniciativas políticas). Para despertar a simpatia da opinião pública, em sua maioria de origem urbana, ele apelava para os seus valores morais e sentimentos humanitários, argumentando que

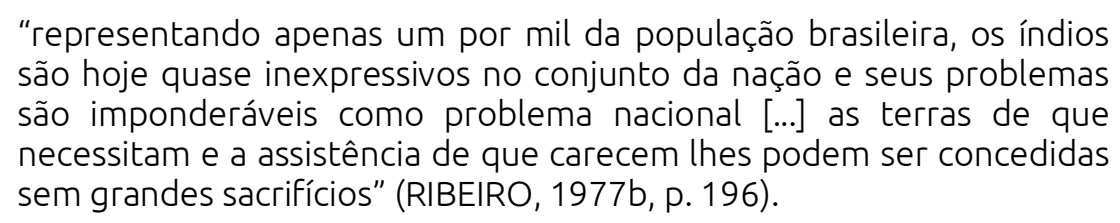

Nos últimos anos, para compreender a questão indígena no Brasil, foi necessário redimensioná-la, utilizando outros parâmetros que não aqueles adotados por Darcy Ribeiro. Se não reduzirmos a questão indígena à sua dimensão demográfica, mas a tratarmos por seu aspecto fundiário, verificamos que afeta $18,4 \%$ da superfície da região amazônica e mais de 10\% de todo território nacional (PACHECO DE OLIVEIRA, 1998, p. 34-36). Não cabe esquecer ainda que essas terras estão situadas em sua maioria em áreas de grande importância para a

\footnotetext{
${ }^{9}$ Ver neste sentido os estudos desenvolvidos pelo Projeto Nova Cartografia Social da Amazônia, coordenado por Alfredo Wagner Berno de Almeida, na Universidade Estadual do Amazonas (UEA).
} 
proteção ao meio-ambiente em escala mundial e para a preservação da biodiversidade, isso sem contar os recursos hídricos, as jazidas minerais e os fatores geopolíticos.

A consideração de todas essas variáveis leva a perceber como o indigenismo rondoniano ${ }^{10}$ tornou-se, nos últimos anos, algo inteiramente obsoleto, incapaz de explicar a complexa cena política. As relações interétnicas não são mais fatos exclusivamente locais, nelas intervindo igualmente diversos organismos de governo e agências internacionais. Embora o Estado brasileiro continue a ser responsável em última instância pelo bem-estar e pelo respeito aos direitos dos índios (como de resto de qualquer cidadão brasileiro), não mais possui um poder de tutela sobre eles, que se fazem representar por organizações próprias, que já operam com recursos e parcerias múltiplas, mobilizando apoios em muitos níveis de ação (PACHECO DE OLIVEIRA, 2016b).

Se na conjuntura atual o diagnóstico de Darcy Ribeiro sobre o problema indígena exige grandes modificações e sua proposta de ação indigenista perdeu a utilidade, o mesmo não se pode dizer de conceitos como o de transfiguração, de muitas de suas observações sobre a teoria do contato interétnico e dos padrões de trabalho por ele preconizados para a antropologia. A sua contribuição à disciplina não deve ser abordada de modo estritamente pessoal e individualizador. É necessário contextualizar as suas posições no diálogo com um grupo de antropólogos brasileiros que the eram contemporâneos (sobretudo com a obra de Roberto Cardoso de Oliveira, que apoia a teoria do contato interétnico em outros pressupostos teóricos), bem como com as propostas do chamado Grupo de Barbados ${ }^{11}$.

As últimas décadas colocaram na ordem do dia a revisão de procedimentos para o exercício do trabalho do antropólogo, buscando dissociá-lo das categorias e práticas do colonialismo e estabelecer novas bases para a disciplina. É dentro deste movimento, acredito, que uma retomada da produção e das intervenções de Darcy Ribeiro deve ser realizada, pois ele aponta para os cientistas brasileiros uma direção original e crítica - a de uma ciência social consciente de seu enraizamento em uma conjuntura histórica específica (vide PACHECO DE OLIVEIRA, 2016d), preocupada com o exercício da pesquisa empírica e com a elaboração teórica compromissada com os grupos sociais desfavorecidos.

\section{REFERÊNCIAS}

AIRES, Max Maranhão P. (Org). Escolas indígenas e políticas interculturais no Nordeste brasileiro. Fortaleza: EDUECE, 2009.

BUARQUE DE HOLANDA, Sérgio. Raízes do Brasil. Rio de Janeiro: José Olympio, 1936.

\footnotetext{
${ }^{10}$ Para uma análise mais detida do SPI e da tradição de conhecimento que inspirou, vide Souza Lima (1995).

11 Vide Dostal (1972) e Declaração de Barbados (25/30 de janeiro de 1971). 
CARDOSO DE OLIVEIRA, Roberto. 0 papel dos Postos Indígenas no processo de assimilação. In: A Sociologia do Brasil Indígena. Brasília: UNB, 1972. p. 20-27.

DOSTAL, Walter (0rg.). The situation of the indian in South American: contributions to the study of inter-ethnic conflict in the non-Andean regions of South America. Geneva: World Council of Churches, 1972.

FREYRE, Gilberto. Casa-grande \& Senzala: formação da família brasileira sob o regime de economia patriarcal. Rio de Janeiro: José Olympio, 1933.

GRUNBERG, Georg (0rg.). Articulación de la diversidad: tercera reunión de Barbados. Quito: AbyaYala, 1995.

NASCIMENTO, Rita Gomes do. Rituais de resistência: experiências pedagógicas Tapebas. 2009. Tese (Doutorado em Educação) - Centro de Ciências Sociais Aplicadas - Universidade Federal do Rio Grande do Norte - Natal, 2009.

PACHECO DE OLIVEIRA, João (0rg.). A viagem da volta: etnicidade, política e reelaboração cultural no Nordeste indígena. $2^{\mathrm{a}}$ ed. Rio de Janeiro: Contra Capa, 2004.

Galvão e os estudos de aculturação no Brasil. In: FAUHABER, P.; TOLEDO, P. M. (Orgs.). Conhecimento e fronteira: história da ciência na Amazônia. Belém: Museu Paraense Emílio Goeldi, 2001. p. 205-222.

(0rg.). Indigenismo e territorialização: poderes, rotinas e saberes coloniais no Вrasil contemporâneo. Rio de Janeiro: Contra Capa, 1998.

0 nascimento do Brasil: revisão de um paradigma historiográfico. In: 0 nascimento do Brasil e outros ensaios: "pacificação", regime tutelar e formação de alteridades. Rio de Janeiro: Contra Сара, 2016a. p. 45-74.

Regime tutelar e globalização: um exercício de sociogênese dos atuais movimentos indígenas no Brasil. In: 0 nascimento do Brasil e outros ensaios: "pacificação", regime tutelar e formação de alteridades. Rio de Janeiro: Contra Capa, 2016b. p. 265-288.

Sem a tutela, uma nova moldura de nação. In: 0 nascimento do Brasil e outros ensaios: "pacificação", regime tutelar e formação de alteridades. Rio de Janeiro: Contra Capa, 2016c. p. 289316. $112,2016 \mathrm{~d}$

Tradiciones etnográficas y formas de construcción de la otredad. Interdisciplina, v. 4, n. 9, p. 93. Uma etnologia dos "índios misturados"? Situação colonial, territorialização e fluxos culturais.

In: 0 nascimento do Brasil e outros ensaios: "pacificação", regime tutelar e formação de alteridades. Rio de Janeiro: Contra Capa, 2016e. p. 193-228.

PACHECO DE OLIVEIRA, João; ROCHA FREIRE, Carlos Augusto da. A presença indígena na formação do Brasil. Brasília: Ministério da Educação/LACED/Museu Nacional, 2007. 
PIRES MENEZES, Maria Lúcia. Parque Indígena do Xingu: a construção de um território estatal. Campinas/São Paulo: UNICAMP/Imprensa Oficial do estado de São Paulo, 2000.

RIBEIRO, Darcy. As Américas e a civilização. Estudos de antropologia da civilização. Rio de Janeiro: Vozes, 1977a.

. Antropologia ou a teoria do bombardeio de Berlim (entrevista). Encontros com a Civilização Brasileira (n 12). Rio de Janeiro: Civilização Brasileira, 1979a.

A política indigenista brasileira. Rio de Janeiro: Ministério da Agricultura, 1962.

Diários índios: os Urubu-Kaapor. São Paulo: Companhia das Letras, 1996.

. Ensaios Insólitos. Porto Alegre: L\&PM, 1979b.

. Gentidades. Porto Alegre: L\&PM, 1997.

. Os índios e a civilização: a integração das populações indígenas no Brasil moderno. Petrópolis: Vozes, $1977 b$.

. 0 povo brasileiro: a formação e o sentido do Brasil. São Paulo: Companhia das Letras, 1995.

1968

0 processo civilizatório: etapas da evolução sócio-cultural. Rio de Janeiro: Civilização Brasileira,

Religião e mitologia Kadiwéu. Rio de Janeiro: Ministério da Agricultura/ Conselho Nacional de Proteção aos Índios, 1950.

(Org.). Summa etnológica brasileira. Petrópolis: Vozes, 1986.

Teoria do Brasil. Rio de Janeiro: Paz e Terra, 1972.

RIBEIRO, Darcy; RIBEIR0, Berta Gleiser. Arte plumária dos índios Kaapor. Rio de Janeiro: Museu do Índio, 1957.

SANTOS, Gersem Luciano dos. 0 índio brasileiro: 0 que você precisa saber sobre os povos indígenas no Brasil de hoje. Brasília: SECAD/MEC, 2007.

SOUZA LIMA, Antonio Carlos de. Um grande cerco de paz: poder tutelar, indianidade e formação do Estado no Brasil. Petrópolis: Vozes, 1995.

STEWARD, Julian (Org.). Handbook of south american indians. Washington: Smithsonian Institute, 1946.

ZARUR, George Cerqueira Leite. Envolvimento de antropólogos e desenvolvimento da antropologia no Brasil. Boletim do Museu do Índio (nº 4). Rio de Janeiro: FNI, 1976.

Recebido em 27 de abril de 2020. Aprovado em 7 de julho de 2020. 